\title{
Normative Visual Development: efficient coding principles for adult V1 predict properties of LGN waves prior to eye opening
}

\author{
Mark V Albert ${ }^{1,2^{*}}$, David J Field ${ }^{2}$ \\ From Nineteenth Annual Computational Neuroscience Meeting: CNS*2010 \\ San Antonio, TX, USA. 24-30 July 2010
}

We present a novel approach to understanding spontaneous activity in the LGN and V1 prior to natural visual experience. Patterned, spontaneous neural activity has been measured in these areas but is poorly understood in comparison to work on retinal waves [1]. Our predictions about LGN/V1 spontaneous activity not only have implications for future experiments, but provide an additional computational-level interpretation. In the same way that V1 can be understood through neural network receptive field models (Marr's algorithmic level) as well as an efficient coding of natural images (Marr's computational level), we propose that early visual spontaneous activity can be understood not only through neural network models of receptive field and map formation, as in many previous approaches [2,3], but also by how this activity relates to the high-level coding objectives of V1.

The key insight in this work is that the form of spontaneous activity in the early visual system can be constrained by these normative principles to resemble measured spontaneous activity patterns. The neural code in fully-developed adult primary visual cortex (V1) is presumed to be an efficient code; by encoding images of our natural visual environment, techniques such as sparse coding [4] and independent components analysis [5] have produced linear filters which resemble experimentally measured receptive fields in V1. Our simulations show how patterns which qualitatively resemble such activity are capable of producing these V1-like visual codes by using the same learning algorithms. The spontaneous activity model is similar to a previous abstracted version of retinal wave generation [6] with

\footnotetext{
* Correspondence: mva6@cornell.edu

'Sensory Motor Performance Program, Northwestern University, Chicago, IL, 60611, USA
}

the addition of multiple eye-layers and correlated interaction between the layers as has been measured experimentally [7]. All model parameters have a direct physiological interpretation and also relate to theoretical models used in the physics of critical phenomena (e.g. percolation networks). This normative approach demonstrates that binocular disparity-selective cells can be refined by spontaneous activity in a way that promotes early stereopsis. This unique, normative approach to visual development provides a way of applying the tools of efficient coding used in the adult visual system to better understand how the how V1 refines prior to visual experience.

\section{Acknowledgements}

We thank Risto Miikkulainen for his helpful comments. This research was supported by National Geospatial-Intelligence Agency contract HM 1582-05C-0007 to DJF and an NSF graduate research fellowship to MVA.

\section{Author details}

'Sensory Motor Performance Program, Northwestern University, Chicago, IL, 60611, USA. ${ }^{2}$ Field of Computational Biology, Department of Psychology, Cornell University, Ithaca, NY, 14853, USA.

\section{Published: 20 July 2010}

\section{References}

1. Huberman AD, Feller MB, Chapman B: Mechanisms underlying development of visual maps and receptive fields. Annu Rev Neurosci 2008, 31:479-509.

2. Swindale NV: The development of topography in the visual cortex: a review of models. Network 1996, 7(2):161-247.

3. Miikkulainen R, Bednar JA, Choe $Y$, Sirosh J: Computational Maps in the Visual Cortex. Springer 2005.

4. Bell AJ, Sejnowski TJ: The "independent components" of natural scenes are edge filters. Vision Research 1997, 37(23):3327-3338.

5. Olshausen BA, Field DJ: Emergence of simple-cell receptive field properties by learning a sparse code for natural images. Nature 1996, 381(6583):607-609. 
6. Albert MV, Schnabel A, Field DJ: Innate visual learning through spontaneous activity patterns. PLoS Computational Biology 2008, 4(8).

7. Weliky M, Katz LC: Correlational structure of spontaneous neuronal activity in the developing lateral geniculate nucleus in vivo. Science 1999, 285(5427):599-604

doi:10.1186/1471-2202-11-S1-P77

Cite this article as: Albert and Field: Normative Visual Development: efficient coding principles for adult V1 predict properties of LGN waves prior to eye opening. BMC Neuroscience 2010 11(Suppl 1):P77.

Submit your next manuscript to BioMed Central and take full advantage of:

- Convenient online submission

- Thorough peer review

- No space constraints or color figure charges

- Immediate publication on acceptance

- Inclusion in PubMed, CAS, Scopus and Google Scholar

- Research which is freely available for redistribution

Submit your manuscript at www.biomedcentral.com/submit
C Biomed Central 